\title{
Diagnostic Pathway for Epididymo-Orchitis
}

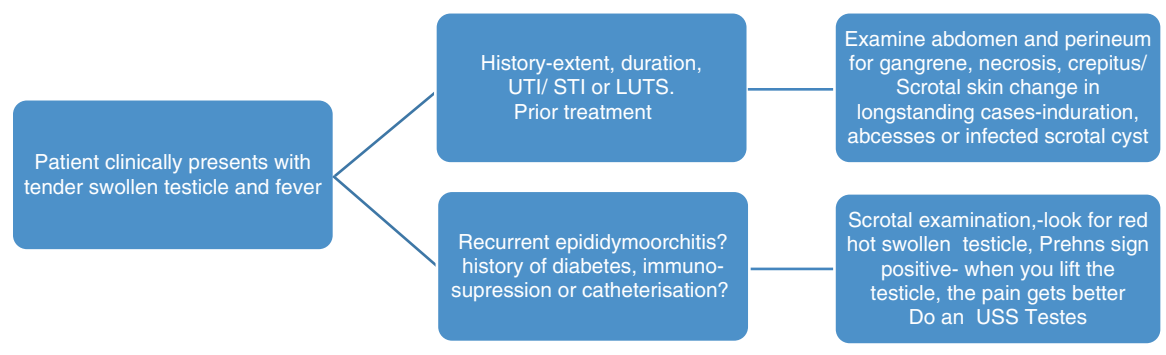

\section{Suggested Reading}

Herbener TE. Ultrasound in the assessment of the acute scrotum. J Clin Ultrasound. 1996;24(8):405-21.

Naber KG, Bergman B, Bishop MC, Bjerklund-Johansen TE, Botto H, Lobel B, Jinenez Cruz F, Selvaggi FP. EAU guidelines for the management of urinary and male genital tract infections. Urinary Tract Infection (UTI) Working Group of the Health Care Office (HCO) of the European Association of Urology (EAU). Eur Urol. 2001;40(5):576-88.

Stewart A, Ubee SS, Davies H. Epididymo-orchitis. BMJ. 2011;342:d1543. 